\title{
HIGH SPEED IMPACT PROPERTIES OF CARBON-BASALT- FLAX DHEC COMPOSITES COMPARED WITH PURE CARBON FIBRE COMPOSITES
}

\author{
E. Nisini ${ }^{*}$, C.Santulli ${ }^{\#}$, A.Ceruti ${ }^{*}$, A.Liverani ${ }^{*}$ \\ *Department of Industrial Engineering, University of Bologna, Italy \\ ${ }^{\#}$ School of Architecture and Design, University of Camerino, Italy
}

\begin{abstract}
A new composite material, defined as Ductile High Energy Composite (DHEC), is analysed in this paper, with particular reference to the energy absorbed after high speed impacts and to the relevant failure mode. A set of DHEC and pure carbon fibre laminates presenting equal weight, equal bending strength or equal stiffness, respectively, have been compared measuring the energy absorbed after the impact of a bullet, through the difference between the total energy of the bullet and the one corresponding to its penetration in a wooden block after hitting the specimens. Fracture modes have been investigated using an optical microscope. Energy absorbed by DHEC laminates is of the same order than for pure carbon ones; however, the DHEC failure mode (referred to as "petaling") presents a lower spreading of splinters respect to the pure carbon fibres (brittle fracture) case. Even though a wider testing campaign is necessary to better evaluate the DHEC properties, they appear to be suitable for adoption in all those applications where impacts can be harmful for end-users or people. Further research on high energy absorption properties is needed to better characterize these innovative composite materials, yet the outcome of this study suggests the high potential of DHEC.
\end{abstract}

\section{INTRODUCTION}

For several reasons, including reduced weight and easier fabrication of complex geometries, composite laminates, such as carbon fibre reinforced composites, are increasingly being used in industrial products. This trend can be noticed not only for advanced applications, like in aerospace, where the aluminium is often replaced by carbon fibre, but also in automotive engineering, production of sports equipment, marine applications. Composite materials based on carbon fibres present high strength to weight ratios, a characteristic though that is obtained at the price of a reduced ductility. This can be particularly dramatic in the case that hidden defects are abruptly and unexpectedly generated, like when a sudden hit creates a delamination on a composite acting as a starting point for crack propagation. Another effect of brittleness is that the energy absorbed by a carbon fibre product after impact may be considerably low. This is a drawback in all the applications where energy should be absorbed by a structure, such as in a car crashing on an obstacle or impacting e.g., with pedestrians. A commonly used method to evaluate the ability of a part to absorb energy is the performance of ballistic tests. So far, there are a number of experimental studies on the ballistic impact of composite materials [1-5]. Tests confirmed that the ballistic limit of polymer composite plates increases with the decreasing strength of the matrix when subjected to shear loading [6]. Moreover, a direct proportionality has been encountered between velocity and trace depth for polymer-based composites [7]. Major energy dissipation mechanisms during ballistic impact of composites include elastic deformation, matrix cracking, delamination and failure of fibres [8].

More specifically, laminated armours with ceramic front layer and composite backing layer were proved having significant potential on saving weight, compared to steel for comparable ballistic loading [9]. The fundamental point, in studying the performance against ballistic impact of an 
armour, is the study of the penetration cone [10]. In this regard, in the composite armour, ceramic plate breaks up, eroding the projectile and increasing the contact surface of the metallic plate: this would occur by forming a hard cone, reducing the local pressure in the backup, whereas the composite backup absorbs the kinetic energy of the projectile and supports the ceramic fragments [11]. An effect similar to that provided by ceramic layers is offered also by the application of polyurea on a steel plate. In particular, polyurea is capable of combining the complex mechanical behaviour, typical of hard rubbers, characterized by large strains, hysteresis, rate sensitivity, stress softening with stress-strain curve depending on the maximum loading previously encountered (Mullins effect), and deviatoric (tending to distortion) and volumetric (tending to change of volume) plasticity [12].

Another aspect that has been very limitedly investigated was the possible (partial or total) replacement of carbon fibres with other reinforcements to obtain composites able to better withstand ballistic impact. Investigated possibilities concerned in particular the replacement of carbon fibres with plant fibres in polypropylene composites obtained by compression moulding for ease of fabrication, in which case flax composites exhibited better energy absorption than hemp and jute composites, while, with a mild steel backing, the best performance was offered by hemp [13]. Also basalt obtained some interest in composites for ballistic application, in particular in the geometry of 2D plain woven fabric in a vinylester matrix with impact damage being dissipated also along the warp and the weft of the textile [14].

The results presented in this paper are complementary to the newest trend in research on high velocity impact properties of laminates, witnessed by recent books [15] and journal papers [16] on these topics. In particular, on ballistic impact properties of hybrid laminates including fibres other than carbon therefore aiming at their possible replacement there is basically no coverage in literature. It is suggested that given the highly dynamical characteristic of ballistic impact, hybridisation would be likely not to lead to a kind of "rule of mixtures" situation from the properties of the originating laminates, especially whenever three different fibres are used.

In this work, the ballistic properties of DHEC carbon/basalt/flax hybrid laminates have been compared with the behaviour typical of carbon fibre based composite materials, trying to investigate the effect of hybridisation on composites, aimed at obtaining a good compromise between weight, stiffness and resistance to high speed impacts using three fibres of markedly different characteristics. The originality of this paper lies in the "design oriented" approach of the composite dynamic properties comparison and in the material tested. The study of impact behaviour of tested materials has not been addressed by comparing specimens with equal thickness, but with similar engineering parameters, such as stiffness, weight, flexural strength. In particular, stiffness is selected as design parameter when controlling the maximum deformation of the loaded component is important, while comparing components with equal weight is used in lightweight constructions (e.g. aerospace, sport, marine engineering) and flexural strength is a typical design driver to control stresses induced by axial or bending loads.

\section{MATERIALS AND METHODS}

\subsection{DHEC LAMINATES}

Ductile High Energy Composite (DHEC) laminates were obtained using Sika polyurea resin Cr-83 and hardener Cr83 in proportion of 100:30. All fibres used are arranged in a twill weave, in particular carbon (areal weight $\left.200 \mathrm{~g} / \mathrm{m}^{2}\right)$, basalt $\left(380 \mathrm{~g} / \mathrm{m}^{2}\right)$ and flax fibres $\left(350 \mathrm{~g} / \mathrm{m}^{2}\right)$ are used, all of which disposed in a 0-90 orientation. The amount of fibres used for all laminates was 55\% by weight and the stacking sequence used is reported in Figure 1. The laminates are cured in oven at $55^{\circ} \mathrm{C}$ for 12 hours, after which they are cooled down naturally in the oven with heat turned off. 


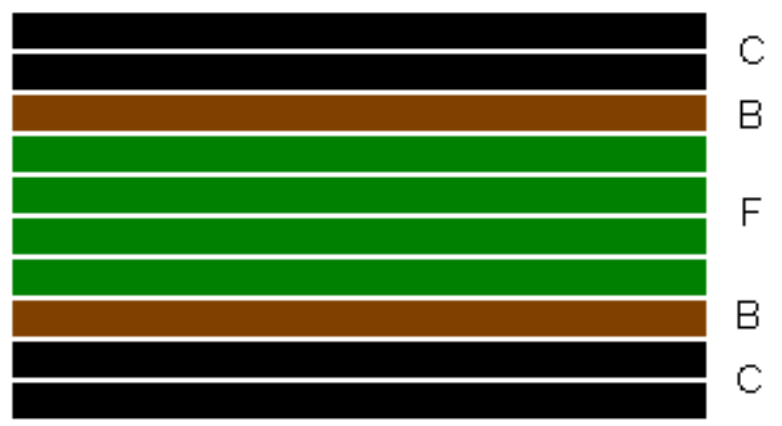

Figure 1 Stacking sequence of DHEC laminate $(C=$ Carbon, $B=$ Basalt, $F=$ Flax $)$

\begin{tabular}{|l|l|l|l|}
\hline \multicolumn{1}{|c|}{ Material } & Number of laminae & \multicolumn{1}{c|}{$\begin{array}{c}\text { Single lamina areal weight } \\
\left(\mathrm{g} / \mathrm{m}^{2}\right)\end{array}$} & \multicolumn{1}{|c|}{ Weight $(\mathrm{g})$} \\
\hline Carbon fibre & 2 & 200 & 25 \\
\hline Basalt & 1 & 380 & 23.75 \\
\hline Flax & 4 & 350 & 95 \\
\hline Basalt & 1 & 380 & 23.75 \\
\hline Carbon fibre & 2 & 200 & 25 \\
\hline Fibre weight (total) & & & 192.5 \\
\hline Resin weight (total) & & & 192.5 \\
\hline Laminate weight & & & $\mathbf{3 8 5}$ \\
\hline
\end{tabular}

Table 1. Lamination table for DHEC specimens (50 wt.\% fibres)

\subsection{TENSILE TESTS}

Tensile tests have been carried out on an Instron 3382 tensile machine equipped with a $100 \mathrm{kN}$ load cell, following ASTM D3039 standard, in displacement control mode at a cross-head velocity of 2 $\mathrm{mm} /$ minute, on samples $250 \mathrm{~mm}$ long and $25 \mathrm{~mm}$ wide. Longitudinal deformation was measured using extensometers Instron model 2630-110.

\subsection{INTERLAMINAR SHEAR STRENGTH (ILSS) TESTS}

ILSS tests have been carried out following ASTM D2344 standard, on a LLOYD Instruments electronic dynamometer, model $30 \mathrm{~K}$, fitted with a $30 \mathrm{kN}$ load cell. The supports for the samples were cylindrical, $3 \mathrm{~mm}$ diameter, while the loading pin was also cylindrical, but with a diameter of $6 \mathrm{~mm}$. All three supports are in AISI316 steel. Loading was carried out in displacement control mode at a cross-head velocity of $1 \mathrm{~mm} /$ minute. Following the standard, samples with square section were used, with a total length equal to six times the thickness and using a testing span equal to four times the thickness.

\subsection{FLEXURAL TESTS}

Flexural tests have been carried out following ASTM D790 standard, again on a LLOYD Instruments electronic dynamometer, model $30 \mathrm{~K}$, fitted with a $30 \mathrm{kN}$ load cell. The supports and the loading pin for the samples all were cylindrical, with a diameter of $5 \mathrm{~mm}$. All three supports are in AISI 316 steel. Loading was carried out in displacement control mode at a cross-head velocity of $1.7 \mathrm{~mm} /$ minute, on samples $90 \mathrm{~mm}$ long and $18 \mathrm{~mm}$ wide using a flexural span equal to $72.5 \mathrm{~mm}$. 


\subsection{HIGH SPEED IMPACT TESTS}

As already stated in the introduction, ballistic tests can be used as a method to evaluate the ability of a part to absorb energy after a high speed impact. In the work described in this paper, several tests have been carried out to evaluate the ballistic performances of the different DHEC and carbon fibre materials considered in this study. The energy absorbed by the laminates is evaluated by shooting a bullet at the specimens and measuring both its initial kinetic energy and the penetration in a wooden block after the specimen has been hit. The facility in which the tests have been carried out is a fire tunnel with a length of around 80 metres. It is composed of a shooting room, connected by a small window to the tunnel: the position where the shooter lies is very close to the window. Several devices isolate the room from the tunnel to increase the safety during tests, and to make accessible the tunnel only when the shooting area is clear. A spruce wooden block (with a diameter of $0.3 \mathrm{~m}$ and a length of $0.25 \mathrm{~m}$ ) has been placed at a distance of 5 meters from the shooting window, while a frame necessary to block the specimens has been placed at a distance of $0.2 \mathrm{~m}$ from the wooden block, along the trajectory of the bullets (see Figure 1). A professional speed measuring system based on high frame cameras is used to evaluate the initial speed of the bullet and to trigger another set of cameras pointing the rear part of the specimens, so that several frames of the impact outcome can be saved. In this way, also considerations on the behaviour of the laminates collapse after being hit by the bullet can be reported. The cartridge used in these tests is a 22 long barrel having a mass of 2.6 grams, fired by a rifle.

The calibre has been selected in order to have a subsonic shot on the target. A set of shots have been carried out on the wooden block to check the precision of the Weigel and Hatscher formula [17]. It was found that to match the penetration in the block available for the experiment, in these formulas $\alpha$ and $\beta$ coefficients required to be modified. The values $\alpha=640$ (Weigel formula) and $\beta=1.7$ (Hatscher formula) provided a value for penetration of $250 \mathrm{~mm}$ with a bullet initial speed of 278 $\mathrm{m} / \mathrm{s}$. In practice, the data have been processed using the Weigel formula with $\alpha=300$ and with the value corrected to match the penetration obtained with the block used in the experiment $(\alpha=640)$. A similar approach has been followed for the Hatscher formula, where computations with the suggested value $\beta=3.5$ have also been carried out with the corrected value $\beta=1.7$.
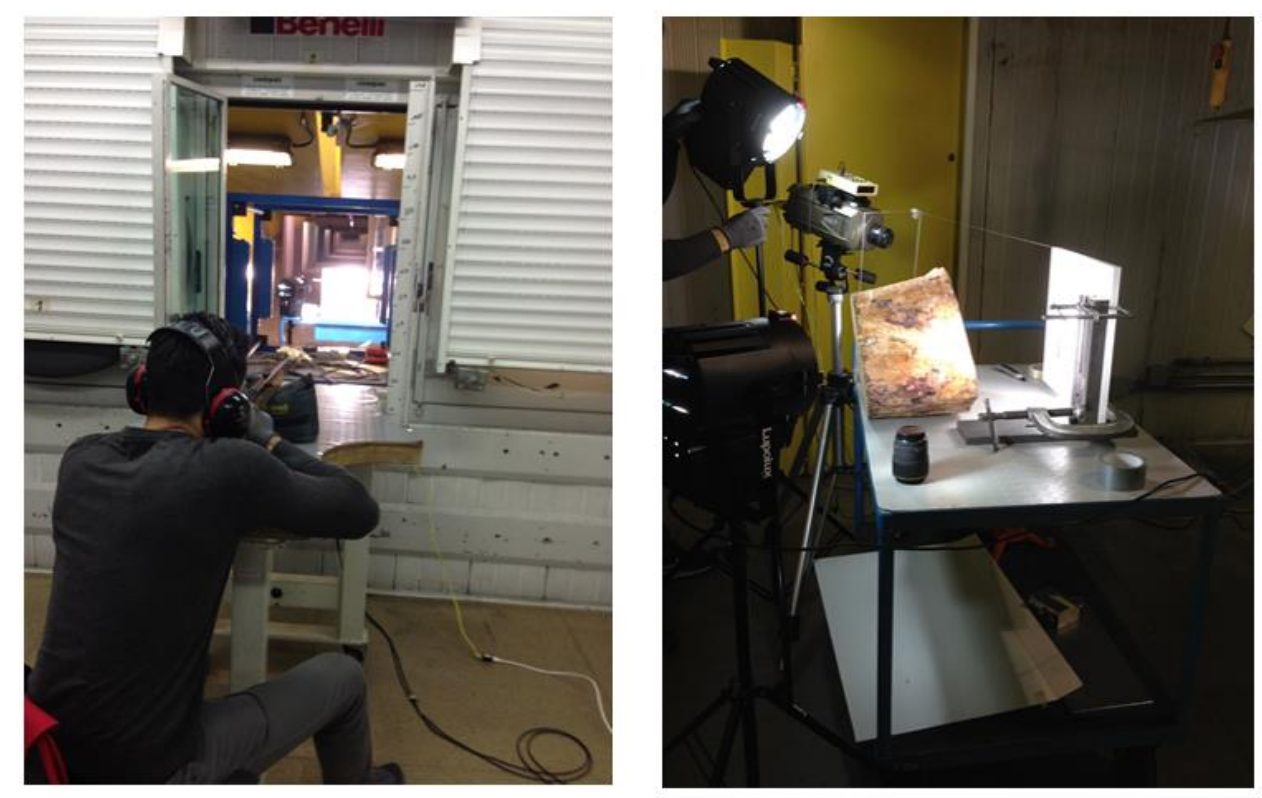

Figure 1 - Experimental set-up for ballistic tests 


\section{RESULTS AND DISCUSSION}

\subsection{COMPARATIVE LAMINATES}

The laminates tested for comparison included only carbon fibres. They were square laminates with sides of $225( \pm 1) \mathrm{mm}$, and thickness variable depending on the lamination type, as from Table 2 . They were all designed to be comparable with the hybrid laminates: in particular, one laminate had the same weight (EW), another had the same bending stiffness (ESF), and the third one the same bending strength (EST). The following considerations allow understanding how comparative laminates were dimensioned.

\begin{tabular}{|l|l|l|}
\hline Laminate & Thickness $(\mathrm{mm})$ & Laminae \\
\hline DHEC & $4.1( \pm 0.1)$ & 10 \\
\hline EW & 3.8 & 15 \\
\hline ESF & 2.7 & 11 \\
\hline EST & 2.5 & 10 \\
\hline
\end{tabular}

Table 2 Thickness and number of laminae of the different laminates

\subsubsection{EW (equal weight)}

Keeping constant fibre content to $55 \mathrm{wt} \%$, the amount of reinforcement of DHEC was equal to a total of $1960 \mathrm{~g} / \mathrm{m}^{2}$. The closest amount of carbon fibres was obtained with 10 laminae weighing 200 $\mathrm{g} / \mathrm{m}^{2}$ each, therefore $2000 \mathrm{~g} / \mathrm{m}^{2}$ in total.

\subsubsection{ESF (equal stiffness)}

\begin{tabular}{|l|l|}
\hline Parameter & Value \\
\hline Tensile strength $(\mathrm{MPa})$ & $185.24 \pm 5.66$ \\
\hline Tensile stiffness $(\mathrm{GPa})$ & $16.89 \pm 0.31$ \\
\hline Flexural strength $(\mathrm{MPa})$ & $286.67 \pm 15.26$ \\
\hline Flexural stiffness $(\mathrm{GPa})$ & $17.08 \pm 1.00$ \\
\hline Interlaminar shear strength $(\mathrm{MPa})$ & $25.35 \pm 0.98$ \\
\hline
\end{tabular}

Table 3 Mechanical tests results

Starting from the flexural modulus $E_{l}=17.08 \mathrm{GPa}$ for DHEC obtained in the experimentation, the average maximum deflection at the maximum breaking load $(F=850 \mathrm{~N})$ is $f_{\max }=3.53 \mathrm{~mm}$. The stiffness $(K)$ of the DHEC specimen can be evaluated by:

$$
k_{D M C}=\frac{F}{f_{M A X}}=\frac{850}{3.53}=240.8 \frac{\mathrm{N}}{\mathrm{mm}}
$$

The thickness of a carbon fibre specimen having the same stiffness $\mathrm{k}$, can be found as follows:

$$
k=\frac{F}{f_{\max }}=\frac{48 E_{c f} I_{c f}}{L^{3}}
$$


$E_{c f}$ represents the elastic module of the carbon fibre stacking, $I_{c f}$ the moment of inertia of the section of the specimen; finally $L$ is the distance between the supports of the test machine. The specimen section is given in this case by a rectangle with height equal to $h_{c f}$, and width $b$, so that its moment of inertia $I_{c f}$ can be computed with:

$$
I_{c f}=\frac{b h_{c f}{ }^{3}}{12}
$$

It is finally possible to provide the thickness of the carbon fibre specimen having the same length between supports $(\mathrm{L}=72.5)$ and width $(\mathrm{b}=18 \mathrm{~mm})$ of the DHEC specimen. It follows in fact, from combining equations (1) and (2), that:

$$
h_{c f}=\sqrt[3]{\frac{k_{D M C} L^{3}}{4 E_{c f} b}}
$$

As a rough approximation, the elastic module of the carbon fibre laminate can be computed basing upon the rule of mixtures [18]:

$$
E_{c f}=E_{f} V_{f}+E_{m} V_{m}=52 G P a
$$

Where $E_{f}=52 \mathrm{GPa}$ is the elastic module of the carbon fibres used in the laminate; $V_{f}=0.55$ is the volumetric ratio between fibres and resin; $E_{m}=4 \mathrm{GPa}$ is the elastic module of the epoxy resin; $V_{m}=0.45$ is the resin volumetric ratio. The thickness of the carbon specimens results equal to $h_{c}=2.9 \mathrm{~mm}$. Assuming the single lamina $0.25 \mathrm{~mm}$ thick, 11 laminae ensure a carbon fibre composite thickness, which provides stiffness equal to that of the DHEC specimen.

\subsubsection{EST (Equal flexural strength)}

In this case, the goal is to produce a carbon fibre reinforced laminate offering the same breaking load of the DHEC specimen during a flexural test. The maximum internal stress in a specimen supported at the ends and loaded in the mid section can be computed with:

$$
\sigma_{\max f}=\frac{M}{I} \frac{h}{2}
$$

where $M$ represents the maximum bending moment offered by the force $F$ times half of the specimen span $h$ and I the inertia of the flexural beam. $\sigma_{\max }$ of carbon fibres has been assumed, according to literature and material data sheet, equal to $\sigma_{\operatorname{maxf}}=660 \mathrm{MPa}$. Also in this case we employed a $200 \mathrm{~g} / \mathrm{m}^{2}$ carbon $0 / 90$ twill fabric, with a fibre/resin ratio $V_{f}=0.55$. The following relations apply for the case study and test constraints:

$$
M=\frac{F_{\max }}{2} \frac{l}{2}
$$

Owing to the rectangular section of the specimen, having a span between supports $L=72.5 \mathrm{~mm}$, and a width $b=18 \mathrm{~mm}$, the inertia of this section $I$ can be computed by:

$$
I=\frac{1}{12} b h^{3}
$$


In this way, the carbon fibre thickness ensuring equal bending strength of the DHEC specimen can be obtained by:

$$
h_{\min }=\sqrt{\frac{3 F L}{2 b \sigma_{\max }}}=2.7 \mathrm{~mm}
$$

Considering the area density of the carbon fibre fabric, equal to $200 \mathrm{~g} / \mathrm{m}^{2}$, and a thickness of 0.25 $\mathrm{mm}$ once cured, the number of laminae necessary to ensure equal bending strength of the DHEC specimen is 10 .

\subsection{EVALUATION OF THE ENERGY ABSORBED BY THE LAMINATES}

To evaluate the energy absorbed by the laminate, a correction was needed to account for the effect of air on the laminate, a first shot was performed without any specimen placed on the target.

In practice, the energy absorbed by the laminates $\left(E_{A}\right)$ was computed as the difference between the initial kinetic energy of the bullet $\left(E_{i}\right)$, and the energy needed by the bullet to penetrate a spruce wooden block $\left(E_{w}\right)$ after hitting the specimen. The initial speed of the bullet $\left(V_{i}\right)$ is computed by professional high performance chronograph system integrated in the tunnel The kinetic energy can be computed by:

$$
E_{i}=\frac{1}{2} m_{b} V_{i}^{2}
$$

where $m_{b}$ stands for the mass of the bullet in $\mathrm{kg}$. Several formulas can be used to correlate the energy absorbed by a wooden block after being hit by a bullet depending on the penetration. In this study, the formulae of Weigel and Hatscher [17] have been used due to the very good prediction of correlation with the spruce wood, as suggested in literature. The Weigel formula predicts the penetration of the bullet in a spruce block in this way:

$$
P=\alpha \frac{m_{b} V^{1.5}}{C^{2}}
$$

Where $P$ is the bullet penetration in millimetres, $V$ is the speed at the impact point in $\mathrm{m} / \mathrm{s}, C$ is the calliper in $\mathrm{mm}, m_{b}$ the bullet mass in $\mathrm{Kg}, \alpha$ an empirical coefficient equal to 300 . Assuming that the mass of the bullet doesn't change after the impact on the specimen and that its speed is constant from the exit from the specimen to the initial impact on the wooden block, it is possible to find $E_{w}$ in Joule by:

$$
E_{w}=\frac{1}{2} m_{b}\left(\frac{P C^{2}}{\alpha m_{b}}\right)^{\frac{4}{3}}
$$

Following the Hatscher formula, the penetration of a bullet in a wooden block can be computed by:

$$
P=\frac{E}{\beta S I}
$$


The value 3.5 is suggested for the value of $\beta$, while $I$ is a shape factor which can be set equal to 1 . Finally, $S$ is the sectional area of the bullet in $\mathrm{mm}^{2}$. The kinetic energy required to produce a hole of length $\mathrm{P}$ in a wooden block can be so computed with Hascher formula by:

$$
\mathrm{E}_{\mathrm{w}}=P \beta S I
$$

The energy absorbed by the laminate can be finally found with the formula:

$$
E_{\mathrm{A}}=\mathrm{E}_{\mathrm{i}}-\mathrm{E}_{\mathrm{w}}
$$

\section{3. $\quad$ EXPERIMENTAL RESULTS OF BALLISTIC TESTS}

Ballistic tests results are reported in Table 4. The large variability of data as far as wood penetration depth, as well as impact energy and ultimately wood absorbed energy is expected in all the comparatively disposed carbon fibre laminates and it should be referred to as the principal difficulty of obtaining repeatable observations from this kind of tests. The effect of DHEC can be viewed in its ability to defragment the projectile, so to lead to the removal of a lower amount of material from the laminates. As from compared data in Figure 2 and 3, it is suggested that no consistent evidence that DHEC specimens absorb less energy can be obtained.

\begin{tabular}{|l|l|l|l|l|l|}
\hline Shot/sample & $\begin{array}{c}\text { Wood penetration } \\
(\mathrm{mm})\end{array}$ & $\begin{array}{c}\text { Projectile velocity at } \\
\text { shotgun exit }(\mathrm{m} / \mathrm{s})\end{array}$ & $\begin{array}{c}\text { Impact } \\
\text { energy }(\mathrm{J})\end{array}$ & $\begin{array}{c}\text { Absorbed } \\
\text { energy }(\mathrm{J})\end{array}$ & $\begin{array}{c}\text { Wood penetration } \\
\text { energy }(\mathrm{J})\end{array}$ \\
\hline & 250 & 278 & 100.47 & & \\
\hline ESF1 & 68.04 & 281.29 & 102.86 & 78.40 & 24.46 \\
\hline ESF2 & 74.7 & 261.44 & 88.86 & 62.01 & 26.85 \\
\hline ESF3 & 113.15 & 307.22 & 122.70 & 82.03 & 40.67 \\
\hline EST1 & 104.3 & 302.57 & 119.01 & 81.52 & 37.49 \\
\hline EST2 & 46.7 & 299.85 & 116.88 & 100.10 & 16.79 \\
\hline EW1 & 37.2 & 291.12 & 110.17 & 96.80 & 13.37 \\
\hline EW2 & 57.32 & 239.23 & 74.40 & 53.80 & 20.60 \\
\hline DMC1 & 87.06 & 262.12 & 89.32 & 58.03 & 31.29 \\
\hline DMC2 & 121.55 & 306.28 & 121.95 & 78.25 & 43.69 \\
\hline DMC3 & 58.44 & 309.6 & 124.61 & 103.60 & 21.01 \\
\hline
\end{tabular}

Table 4 Summary of ballistic tests results 


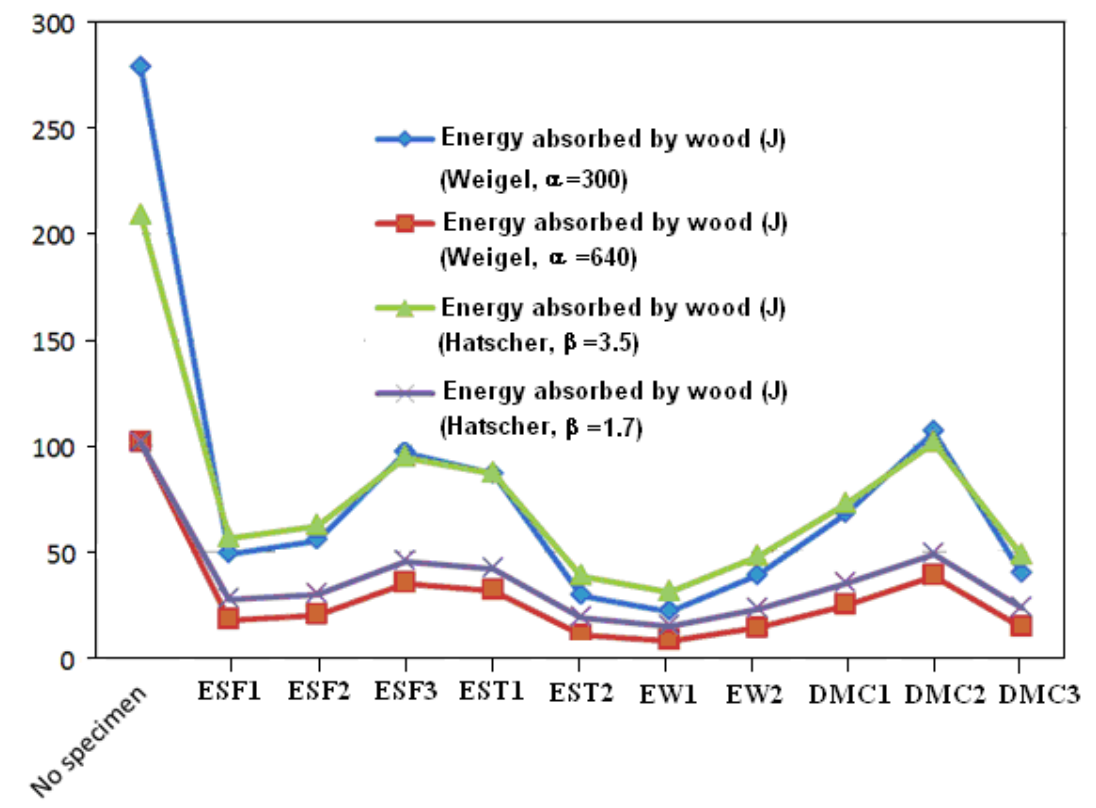

Figure 2. Energy absorbed by wood support according to different Weigel and Hatscher models

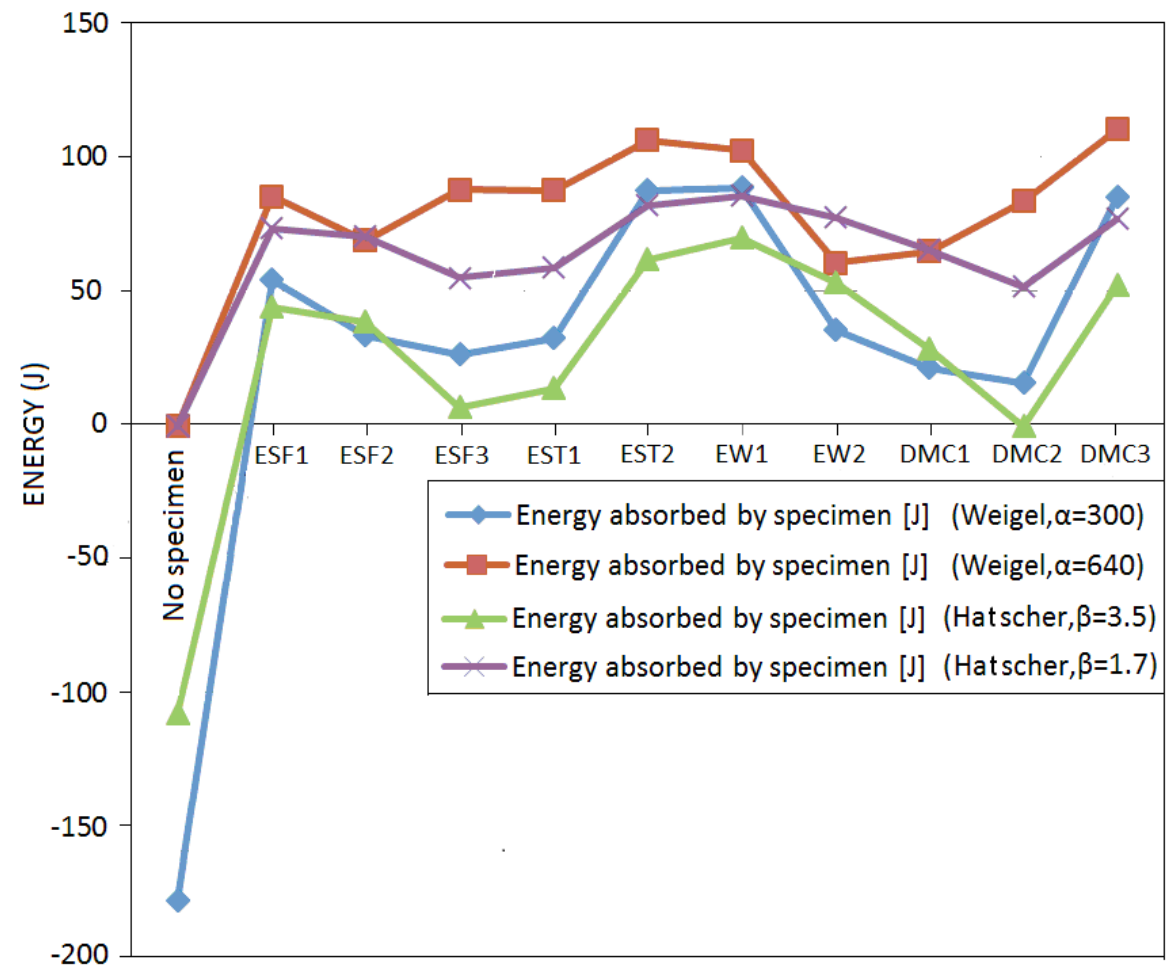

Figure 3. Energy absorbed by specimens according to different Weigel and Hatscher models

The following Figure 4 aims at comparing the mean energy absorbed by the four types of laminates (EW, ESF, EST, DHEC), together with the standard deviation (considering Weigel formula with $\alpha=640$, and Hatscher one with $\beta=1.7$ ). From this picture it can be seen that DHEC performances are similar to that of the carbon fibre. On the other hand, the mode of fragmentation of the laminates needs to be considered due to the significance of this aspect on human health in case of accidents involving composite materials. 


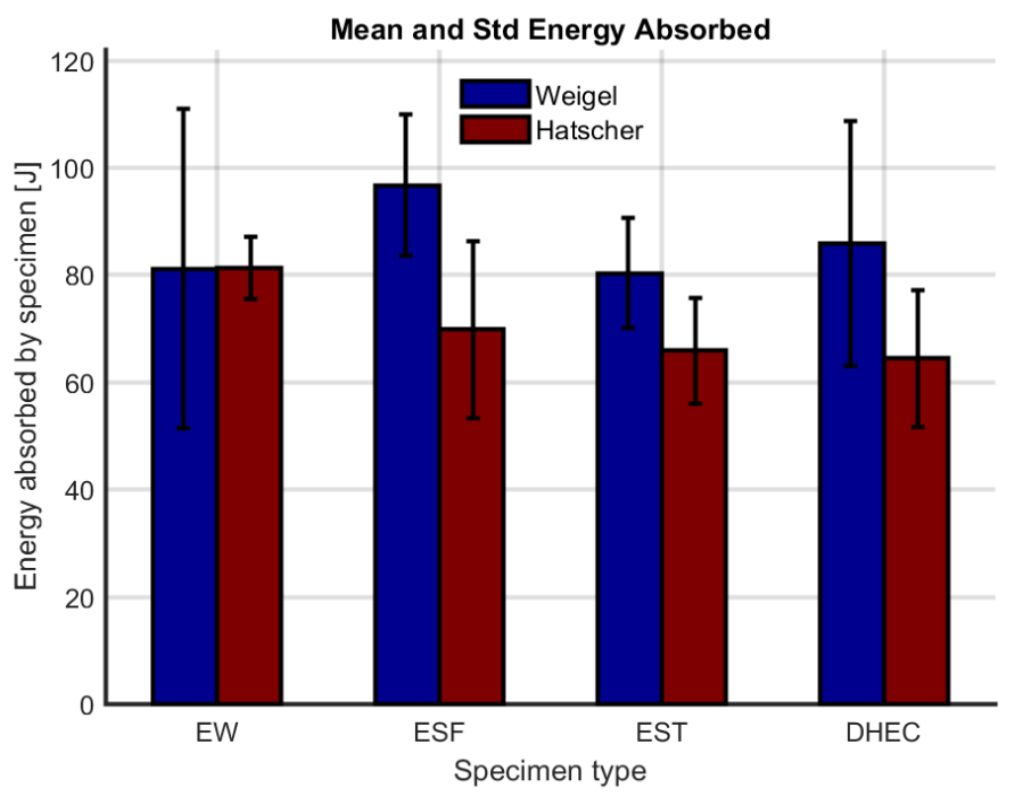

Figure 4. Mean and standard deviation for specimens' absorbed energy with Weigel and Hatscher formula

At this point therefore, a discussion over the morphology of ballistic damage needs to be carried out. It has been previously suggested that different modes of damage exist, which are clearly visible after laminate perforation. In particular, very evident are normally cone formation on the back face of the target, tensile failure of primary yarns and shear plugging on the laminates, the latter being normally prevalent on thick laminates [19-21]. In order to address the reader towards more detailed description of failure modes on laminates, Wambua et al. [13] present a deep description of failure modes for composite materials: after initial damage due to shear forces, a tensile load can damage the material, followed by a delamination around the zone interested by a high speed impact. Localized bulging can be also noticed. On the one hand, Razali et al. [22] state that energy in high speed impacts is absorbed through the following events: moving cone formed on the back face of the impacted object, shear plugging, tensile failure of the primary yarns, elastic deformation of the secondary yarns, matrix cracking and delamination and frictional energy absorbed during penetration. On the other hand, Zuckas [23] proposes to classify failure modes of targets in: Brittle Fracture, Ductile Hole Growth, Fragmentation, Radial Fracture, Plugging, Petaling, describing by a set of pictures the visual aspect of holes depending on the failure mode. 

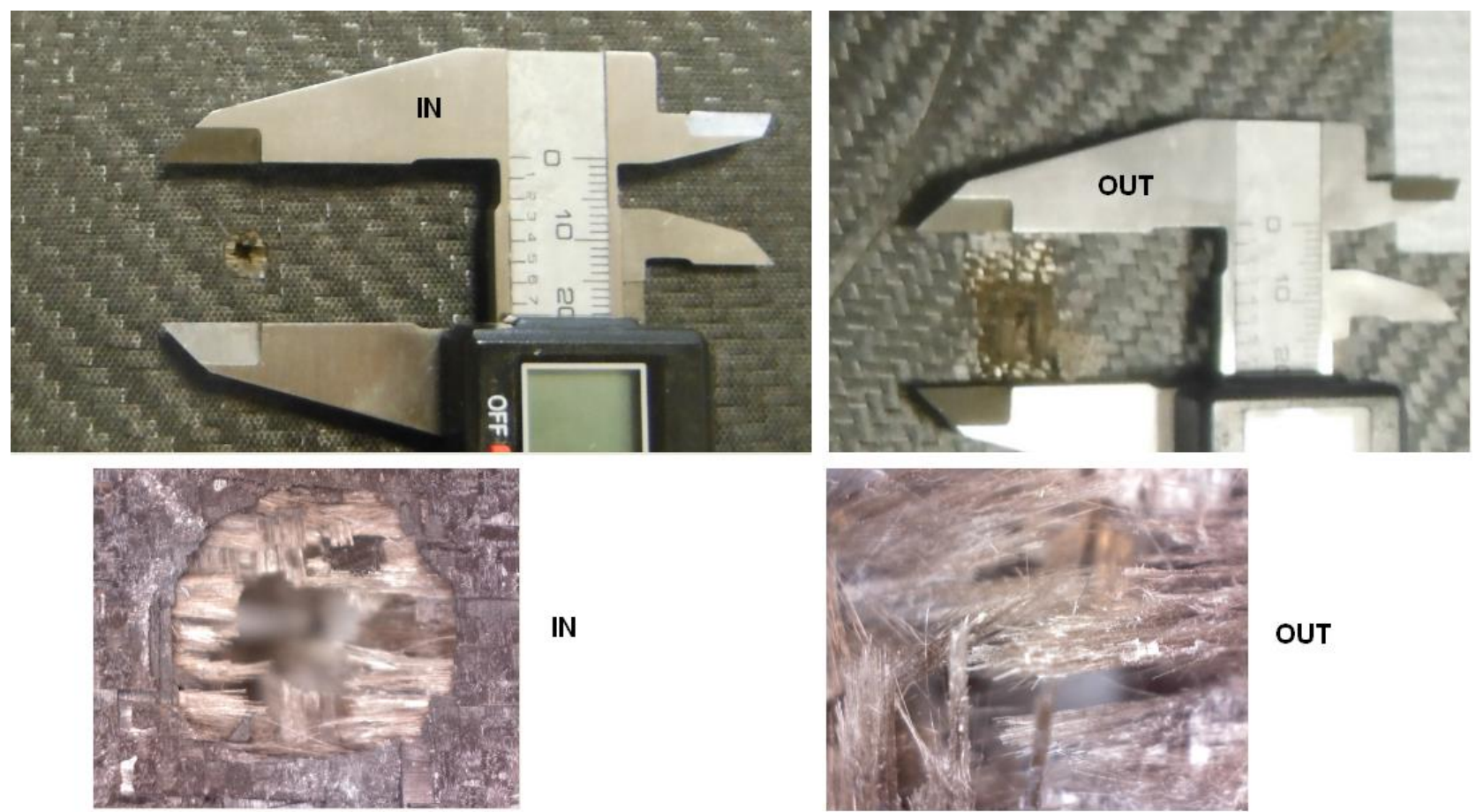

Figure 5 Effect of shot on DHEC laminates
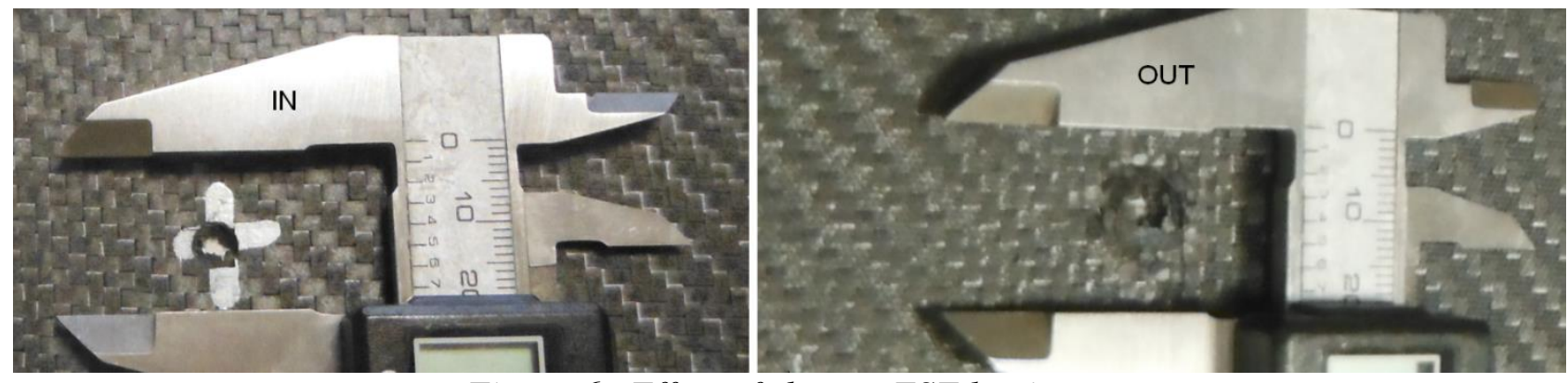

Figure 6a Effect of shot on ESF laminates
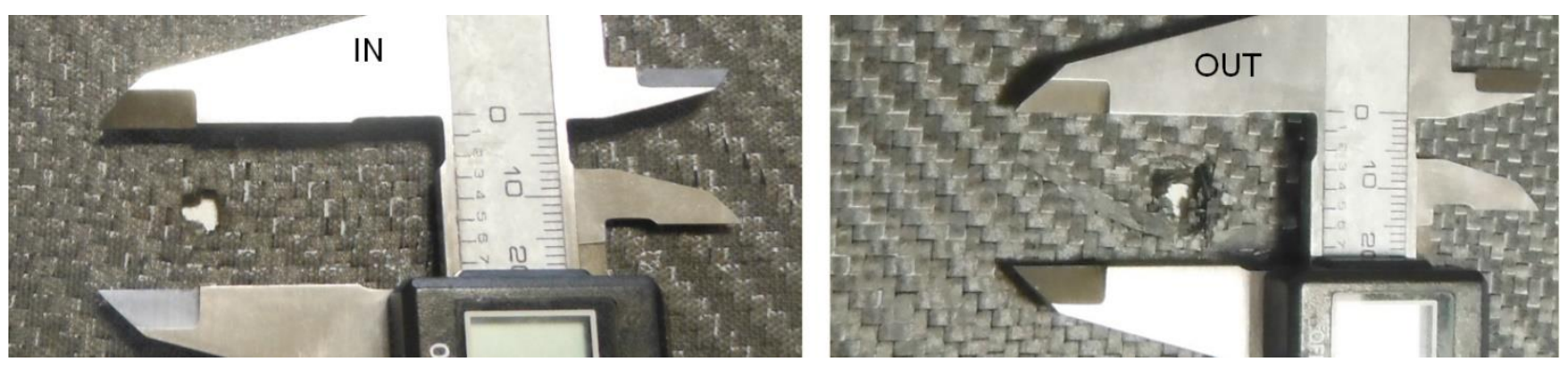

Figure $6 b$ Effect of shot on EST laminates
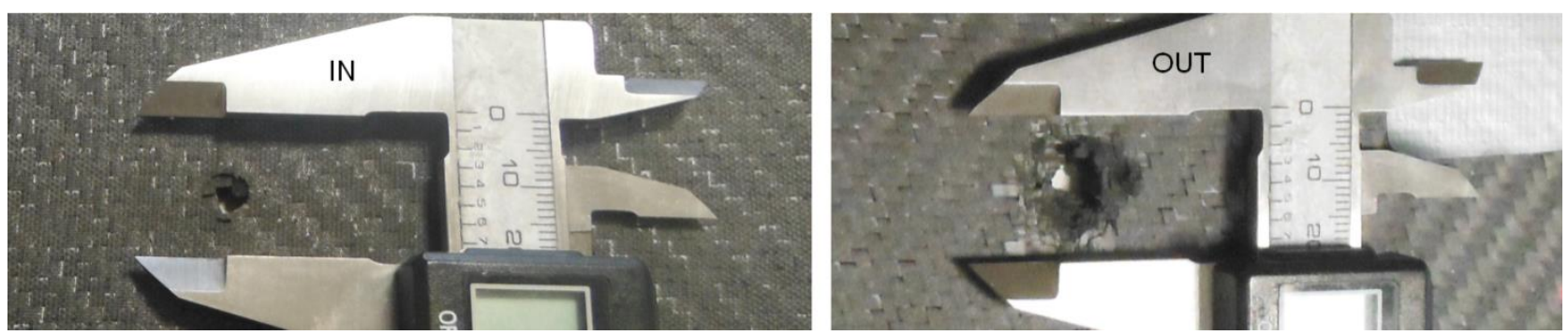

Figure 6c Effect of shot on EW laminates 
As the reference [20] introduces, brittle fracture and petaling are typical failure modes when dealing with high speed impacts. Brittle fracture can be defined as a failure mode which is noticed when a tensile stress acts normal to the crystallographic planes with low bonding during the impact. On the other hand, petaling is obtained when the tensile strength is exceeded in the rear side of the specimen so that cracks develop around the tip of the impacting body assuming a star-like configuration. A set of strip-shaped sectors are than pushed back by the deep penetration of the impacting body forming a sort of petals. Figure 5 and 6 provides pictures of the in and out holes in the four laminates compared in this study. As it can be noticed, in case of DHEC the dimension of the out hole is larger than in other cases, and material still covers the hole zone. On the other hand, the holes in carbon fibre based specimen presents empty space due to the fact that a large amount of fibres have been projected away the impact zone due to a fragile failure, with a large projection of splinters. The following Figure 7 presents a picture of the hole in carbon fibre and in the DHEC material (a section of the hole in this case) obtained using the zooming provided by a microscope.
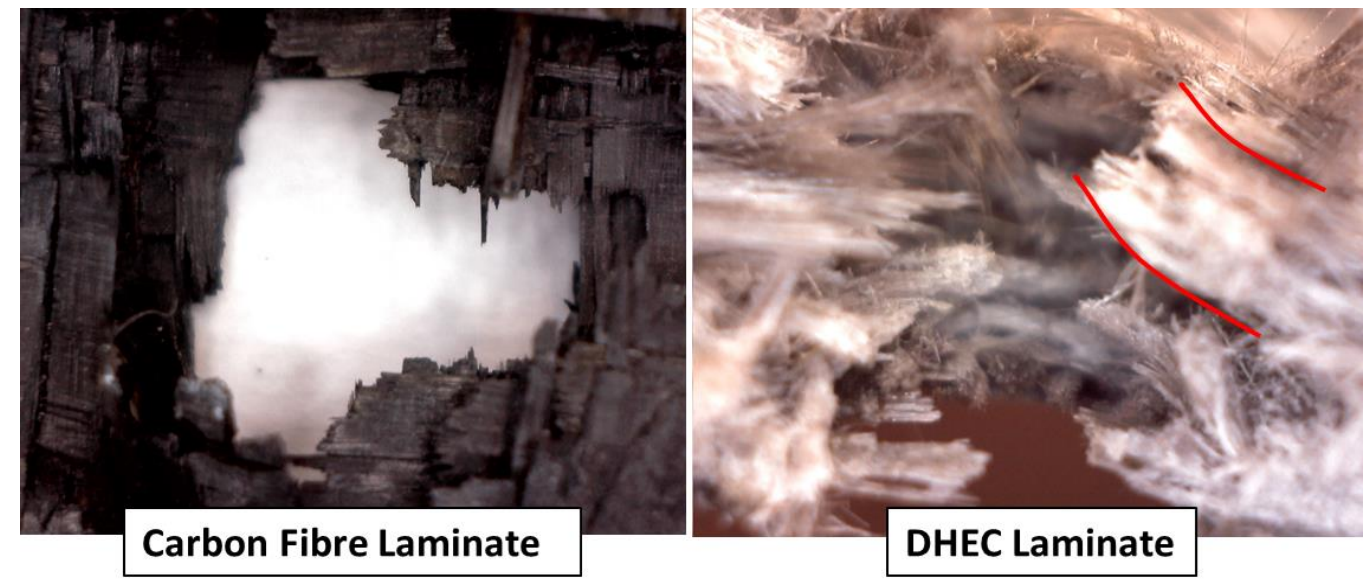

Figure 7 Microscope image of holes in carbon fibre (front view) and DHEC laminates (section)

As it can be noticed by enlarged image, a brittle failure can be seen in carbon fibre based composite: according to literature on laminates failure, the carbon fibres are interrupted due to shear forces leading to filaments breaking. No deformations are noticed; delaminations can be seen due to the effect of the release of high energy in the zone of the main impact. In case of DHEC composite, typical petaling behaviour can be seen due to the "crater shaped" and highly deformed section of the hole.

About splinters diffusion, the following Figure 8 shows a frame of the impact behaviour in case of Carbon Fibre laminates and DHEC material. It is worth noting the dimensions of the fragments after the high speed impact: the drag of a body is proportional to its surface, while its kinetic energy to its mass (provided an equal speed). The capability to arrest the cracks provided by flax yarns has been noticed already in literature [24]. On the other side, the combined effect of the presence of hybrid reinforcement including basalt has been recognised to lead to stepwise failure morphology: as a whole, this can be presented as the origin of petaling phenomenon in failure holes, as more detailed further down [25]. 


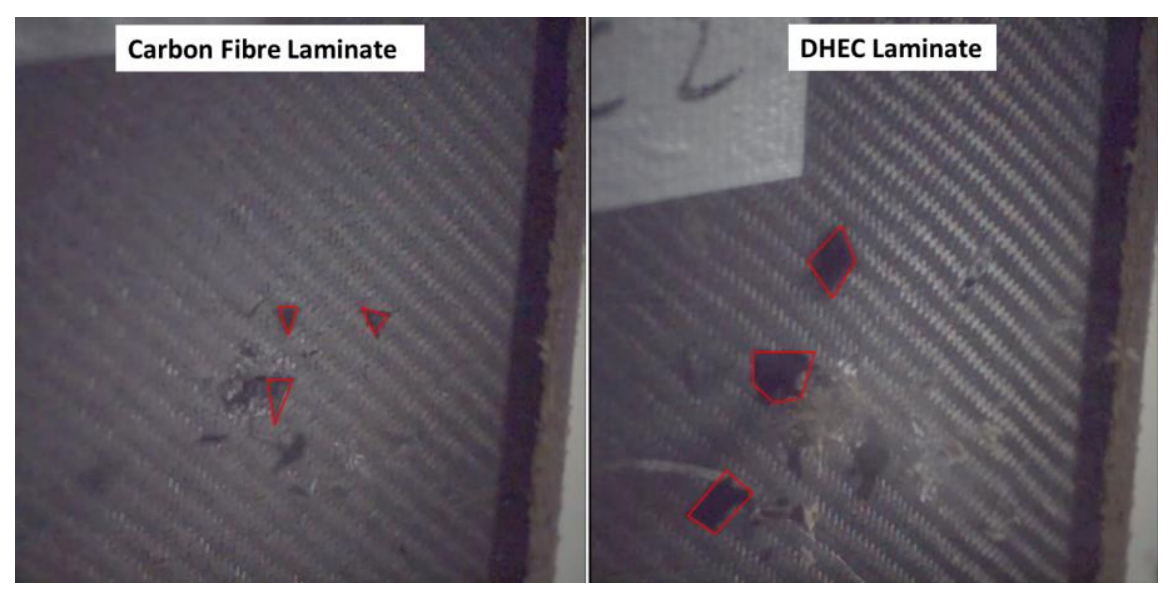

Figure 8 Splinters size and shape with carbon fibre based and DHEC laminate

In case of DHEC petaling occurs and splinters geometry is similar to small sheets presenting a high surface to mass ratio; in case of Carbon Fibre a high fragmentation is noticed with sharp splinters presenting a cylindrical shape with a lower surface to mass ratio, and thus a reduced drag and a high residual kinetic energy and dangerous penetration capability.

Summarizing, the analysis of the failure modes [26] of the specimens under study (see Figure 5 and 6) show a petaling model of fracture in case of DHEC, while in case of pure carbon fibre composite the failure modes match the brittle fracture behaviour. This behaviour is of paramount importance in engineering due to the different consequences on human body in case of impacts on DHEC or pure carbon fibre based composites. In a scenario when a pedestrian is hit by a bump of a car, different health damages are expected with two materials: with pure carbon fibres a lot of fragments are spread from the impact point with a high speed and important penetration capability, with a risk of penetrating in the skin and harms for nerves, circulatory system or internal organs. When a DHEC component is hit at high speed the petaling fracture mode is less dangerous, since less penetrating splinters are projected. Health implication of these facts is important for all components that can be potentially involved in accidents. Being the physical properties of DHEC similar to carbon fibre, its use should be suggested when injury risks are significant.

\section{CONCLUSIONS}

This paper presents a comparison between the behaviour to high speed impacts of DHEC and pure carbon fibre composite materials. A test campaign has been carried out in a firing tunnel where bullets have been fired upon specimens and absorbed energy has been evaluated. Four kinds of specimens have been tested: DHEC, pure carbon fibre with equal weight, equal bending strength, and equal stiffness respect to DHEC. The energy absorbed by specimens has been evaluated using Weigel and Hatscher formulae allowing evaluating the residual energy of the bullets after impacting the specimens. Results obtained show similar values for energy absorbed in all the four cases, namely around $70 \mathrm{~J}$. Also the failure modes have been investigated by inspecting the front and rear side of the specimens. While pure carbon fibre specimens present typical brittle failure behaviour with a huge projection of splinters, the DHEC shows a typical petaling mode in which the fibres are deflected in the penetration direction but without significant spreading of fragments. The outcome of this work is that DHEC composite are more suitable than pure carbon fibre composite where parts can be hit by high speed bodies and it can cause harm to people. Future works will include a larger experimentation with further attention in the manufacturing process of the laminate to try to reduce the standard deviation of absorbed energy over the different laminates. Moreover, to evaluate more precisely the compared ballistic properties of DHEC and pure carbon fibre composites, investigation of the effect of projectile shape would also be needed [27]. As a whole though, the present study confirms that there is scope for using DHEC to withstand high speed 
impacts, reducing therefore as much as possible harm to human beings, especially in view of the presence of hybrid reinforcement drastically changing the way the composite undergoes fracture at high speed.

\section{ACKNOWLEDGMENTS}

Authors wish to thank Benelli Company for sharing the firing tunnel used to perform the tests described in this paper, and in particular Chief Engineer Marco Vignaroli, Testing Engineers Michele Aluigi and Adam Rustum for their help and support.

\section{REFERENCES}

1. Mouritz A.P., 2001, Ballistic impact and explosive blast resistance of stitched composites, Composites Part B, 32, 5, 431-439.

2. Hosur M.V., Alexander J., Vaidya U.K., Jeelani S., 2001, High strain rate compression response of carbon/epoxy laminate composites, Composite Structures, 52, 3/4, 405-417

3. Hosur M.V., Vaidya U.K., Ulven C., Jeelani S., 2004, Performance of stitched/unstitched woven carbon/epoxy composites under high velocity impact loading, Composite Structures 64, 3/4, 455-466.

4. Ubeyli M., Yildirim R.O., Ogel B., 2007, On the comparison of the ballistic performance of steel and laminated composite armors, Materials and Design, 28, 4, 1257-1262.

5. Wiśniewski A., Pacek D., 2013, Experimental research and numerical analysis of penetration of the Twaron T750 aramid fabric with the $9 \mathrm{~mm}$ Parabellum projectile, Problems of Mechatronics. Armament, Aviation, Safety Engineering, 3, 13, 7-22.

6. Karthikeyan K., Russell B.P., Fleck N.A., Wadley H.N.G., Deshpande V.S., 2013, The effect of shear strength on the ballistic response of laminated composite plates, European Journal of Mechanics - A/Solids, 42, 35-53.

7. Tarim N., Findik F., Uzun H., 2002, Ballistic impact performance of composite structures, Composite Structures 56 (1), 13-20.

8. Morye SS, Hine PJ, Duckett RA, Carr DJ, Ward IM, Modelling of the energy absorption by polymer composites upon ballistic impact, Composites Science and Technology 60 (14), 2631-2642.

9. Shokrieh MM, Javadpour GH; Penetration analysis of a projectile in ceramic composite armor, Composite Structures 82 (2), 2008, 269-276.

10. Wilkins ML, Mechanics of penetration and perforation, International Journal of Engineering Science 16 (11), 1978, 793-807.

11. Tasdemirci A, Tunusoglu G, Güden M, The effect of the interlayer on the ballistic performance of ceramic/composite armors: Experimental and numerical study, International Journal of Impact Engineering 44, 2012, 1-9.

12. El Sayed T, Mock Jr W, Mota A, Fraternali F, Ortiz M, Computational assessment of ballistic impact on a high strength structural steel/polyurea composite plate, Computational Mechanics 43 (4), 2009, 525-534.

13. Wambua P, Vangrimde B, Lomov S, Verpoest I, The response of natural fibre composites to ballistic impact by fragment simulating projectiles, Composite Structures 77 (2), 2007, 232240.

14. Niu Z, Jin L, Yu L, Sun B, Chen P, Su J, Ballistic penetration damage of 2D basalt fiber plain woven composite, Advanced Materials Research 487, 2012, 530-533.

15. Hazell, P.J., 'Shock loading of polymer composites', in Silberschmidt VV (ed.), Dynamic Deformation, Damage and Fracture in Composite Materials and Structures, Woodhead Publishing Limited, Oxford, 2016, 337-363. 
16. Li Z; Khennane A; Hazell PJ; Brown AD, 'Impact behaviour of pultruded GFRP composites under low-velocity impact loading', Composite Structures, 2017, vol. 168, 360 - 371.

17. Sellier KG, Kneubuehl BP, Wound Ballistics and the Scientific Background, Elsevier, 1994, ISBN 0-444-81511-2.

18. Gay D, Composite Materials: Design and Applications, Third Edition, CRC Press, 2014, ISBN 9781466584877.

19. Naik NK, Shrirao P, Composite structures under ballistic impact, Composite Structures 66 (1-4), 2004, 579-590.

20. Naik NK, Shrirao P, Reddy BCK, Ballistic impact behaviour of woven fabric composites: Formulation, International Journal of Impact Engineering 32 (9), 2006, 1521-1552.

21. Naik NK, Doshi AV, Ballistic impact behaviour of thick composites: Parametric studies, Composite Structures 82 (3), 2008, 447-464.

22. Razali,N., Sultan,M.T.H., Mustapha,F., Yidris,N., and Ishak,M.R., Impact Damage on Composite Structures - A Review, The International Journal Of Engineering And Science (IJES), 3 (7), 2014, 8-20.

23. Zukas, J.A., "Impact dynamics" John Wiley \& Sons, New York; (1990).

24. Ghasemnejad H, Soroush VR, Mason PJ, Weager B, To improve impact damage response of single and multi-delaminated FRP composites using natural Flax yarn, Materials \& Design 36, 2012, 865-873.

25. Wang X, Hu B, Feng Y, Liang F, Mo J, Xiong J , Qiu Y, Low velocity impact properties of 3D woven basalt/aramid hybrid composites, Composites Science and Technology 68, 2008, 444-450.

26. Voyiadjis, G.Z., Damage Mechanics and Micromechanics of Localized Fracture Phenomena in Inelastic Solids, Springer Science \& Business Media, 2012.

27. Ulven C, Vaidya UK, Hosur MV, Effect of projectile shape during ballistic perforation of VARTM carbon/epoxy composite panels, Composite Structures 61 (1-2), 2003, 143-150. 